\title{
RANCANG BANGUN MESIN PEMBUATAN SARI TAPIOKA PADA PEMROSES GULA CAIR (SIRUP GLUKOSA) DARI SINGKONG (MANIHOT UTILLISSIMA) UNTUK INDUSTRI KECIL MENENGAH
}

\author{
Ig. Jaka Mulyana ${ }^{1}$, L.M. Hadi Santosa ${ }^{2}$, Yuliati $^{3}$ \\ Jurusan Teknik Industri ${ }^{1,2)}$, Jurusan Teknik Elektro ${ }^{3)}$, Universitas Katolik Widya Mandala Surabaya, \\ Jl. Kalijudan 37 Surabaya \\ E-Mail : jmulyono@ukwms.ac.id ${ }^{l}$
}

\begin{abstract}
Sugar is one of the main sources of sweeteners and is widely used in the community. As one of the main ingredients in Indonesia, sugar demand in Indonesia has always increased along with the increase of population and industry growth in Indonesia. Meanwhile, sugar production in Indonesia can not meet domestic demand. Technically, the process of making glucose syrup is relatively simple and can be done by small or medium industries. But in fact glucose syrup producers are almost big industries. This is due to the development of a simple and cheap machine for making liquid sugar. Therefore, it is necessary to develop equipment to produce liquid sugar made from raw cassava, which can be used by small industry to develop liquid sugar industry. The process of making liquid sugar from cassava is divided into three namely the process of making tapioca, liquification and saccharification process and the process of tanning \& filtering and evaporation. In this paper we will discuss the design of tapioca processing equipment which is part of the liquid cassava production equipment made from raw cassava that can be developed by small industry. With this equioment, the community can design a small industry of liquid sugar processing. This equipment aims to process cassava into cassava slurry. It is developed by using the principle of grinding and solvent. The processing capacity is designed to be $300 \mathrm{~kg} /$ hour.
\end{abstract}

Keywords : Liquid Sugar, Cassava, Small Industry.

\section{PENDAHULUAN}

Gula merupakan kebutuhan pokok rakyat yang cukup strategis yaitu sebagai bahan pangan sumber kalori. Gula merupakan salah satu sumber pemanis utama dan digunakan secara luas di masyarakat. Sebagai salah satu bahan pokok di Indonesia, kebutuhan gula di Indonesia selalu meningkat seiring dengan peningkatan pertumbuhan penduduk dan industri di Indonesia. Sementara itu produksi gula di Indonesia tidak dapat memenuhi kebutuhan dalam negeri. Pabrik gula yang berada di P. Jawa, relatif berumur teknis sudah tua, sehingga kurang produktif, hampir semua pabrik gula sangat tergantung pada petani tebu dan dengan lahan yang terbatas di Pulau Jawa. Sementara pabrik gula Rafinasi yang ada (8 pabrik) belum berproduksi secara optimal (utilisasi kapasitas sekitar 40\% - 60 $\%$ pada tahun 2008). Pesatnya perkembangan kebutuhan gula sementara peningkatan produksi relatif belum seimbang menjadikan Indonesia sebagai importir gula baik untuk gula kristal mentah (raw sugar) maupun gula industri (refined sugar) (Roadmap Industri Gula, Direktorat Jenderal Industri Agro Dan Kimia Departemen Perindustrian Jakarta, 2009).

Kebutuhan gula kristal putih pada tahun 2012 sebesar 5,13 juta ton, dimana 2,60 juta ton adalah kebutuhan rumah tangga dan sisanya 2,53 juta ton adalah kebutuhan industri. Sementara jumlah produksi hanya sebesar 2,5 juta ton. Kekurangan kebutuhan dipenuhi melalui impor. Ketergantungan pada import akan terus berlangsung sejalan dengan pertambahan penduduk, dan peningkatan pendapatan masyarakat serta pertumbuhan sektor industri. Kekurangan gula dalam arti luas semakin besar, karena setiap tahun masih mengimpor gula cair (sirup glukosa) dengan rata - rata pertumbuhan sebesar $30 \%$ dan pada tahun 2011 sebesar 73.100 ton dan ekspornya 
sebesar 1.092 ton (Pusdatin Kemenperin, dalam Suripto dkk, 2012).

Untuk memenuhi kebutuhan pemanis adalah dengan mengembangkan industri gula non tebu. Bahan yang dapat diolah menjadi pemanis adalah singkong (Manihot Esculenta). Singkong atau ubi kayu sebagai sumber pati - patian selama ini diketahui masyarakat luas hanya sebagai sumber pangan. Indonesia merupakan penghasil ubi kayu yang cukup besar.

Selain dimanfaatkan menjadi berbagai macam bahan makanan, singkong dapat diolah menjadi bioethanol dan gula cair. Pengolahan ubi kayu dapat menghasilkan berbagai produk seperti tepung gaplek, produk gula cair (sirup glukosa) dan tepung tapioka Produk gula yang dapat diturunkan dari tepung tapioka I ma (casava) terdiri dari tepung gula kasava, sirup glukosa kualitas nomor dua (warna coklat), sirup glukosa kualitas nomor satu (warna bening), dan sirup fluktosa yang 1,5 kali lebih manis dari gula tebu (Sinar Tani, dalam Suripto dkk, 2013).
Secara teknologi, proses pembuatan sirup glukosa relatif sederhana dan dapat dilakukan oleh industri kecil atau menengah. Namun pada kenyataannya produsen sirup glukosa hampir semuanya industri besar (Suripto dkk, 2012). Hal ini disebabkan belum dikembangkannya mesin pembuatan gula cair yang sederhana dan murah. Untuk itu perlu dikembangkan peralatan untuk memproduksi gula cair berbahan baku singkong, yang dapat digunakan oleh industri kecil untuk mengembangkan industri gula cair. Pembuatan gula cair terbagi menjadi 3 tahap yaitu proses pembuatan tapioka, proses likuifikasi, sakarifikasi, pemucatan dan penyaringan serta evaporasi. Dalam makalah ini dibahas tentang rancang bangun mesin pembuatan sari tapioka yang merupakan salah satu bagian dari alat pembuatan gula cair.

\section{METODE PENELITIAN}

\subsection{Proses Pembuatan Tapioka dan Gula Cair}

Secara keseluruhan, alur proses pembuatan gula cair dapat dilihat pada gambar 1 .

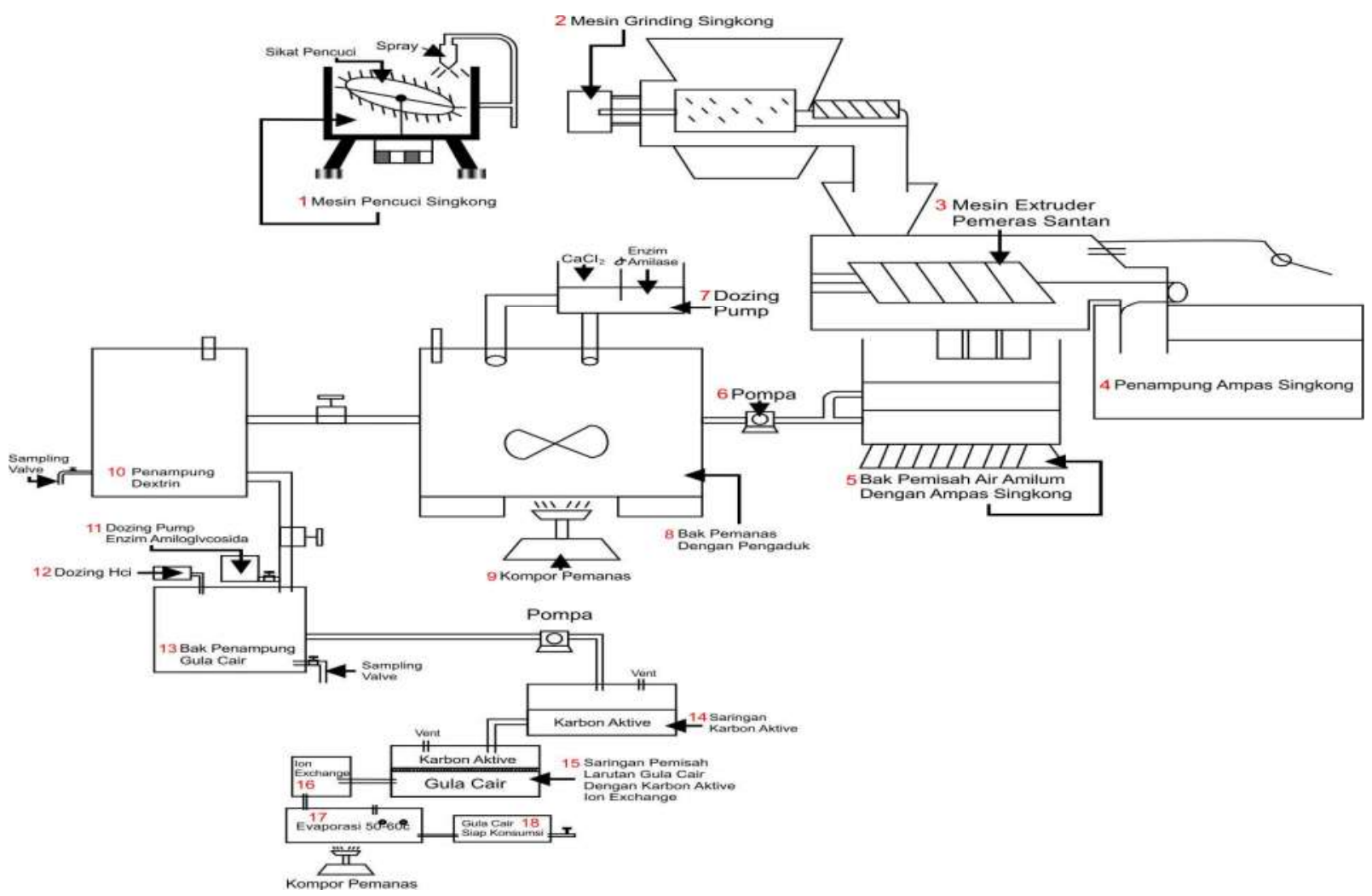

Gambar 1. Alur Proses Pembuatan Gula Cair. 
Bagian alat yang merupakan mekanisme pembuatan sari tapioka adalah bagian mesin pemarut (2) singkong dan pemeras santan (3).

\subsection{Perancangan Mesin Pembuat Tapioka}

Mesin pembuatan sari tapioka ini, secara garis besar dibagi menjadi dua yaitu perancangan dan pembuatan :
1. Mesin Pemarut Singkong.

2. Mesin Pemeras.

Mesin didesain dengan kapasitas 50 $\mathrm{kg} / \mathrm{jam}$. Desain mesin pemarut singkong dapat ditunjukkan pada gambar 2. Mesin pembuatan sari tapioka ini menggunakan satu motor untuk menggerakkan pemarut dan pemeras.

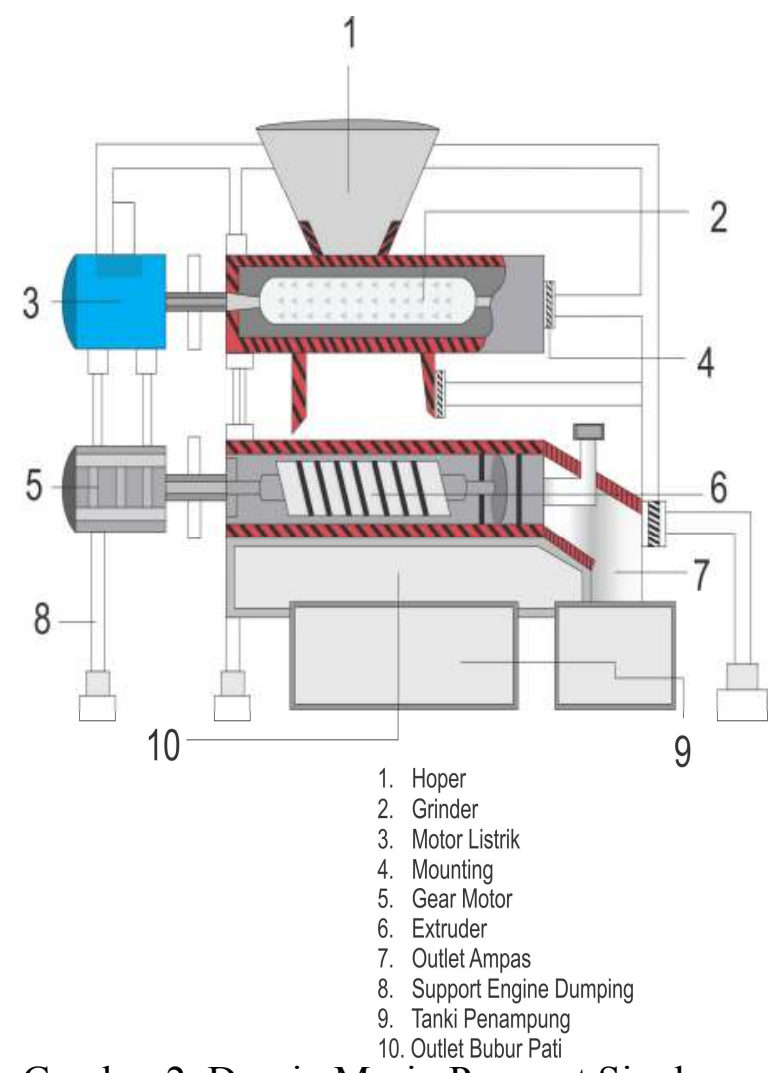

Gambar 2. Desain Mesin Pemarut Singkong.

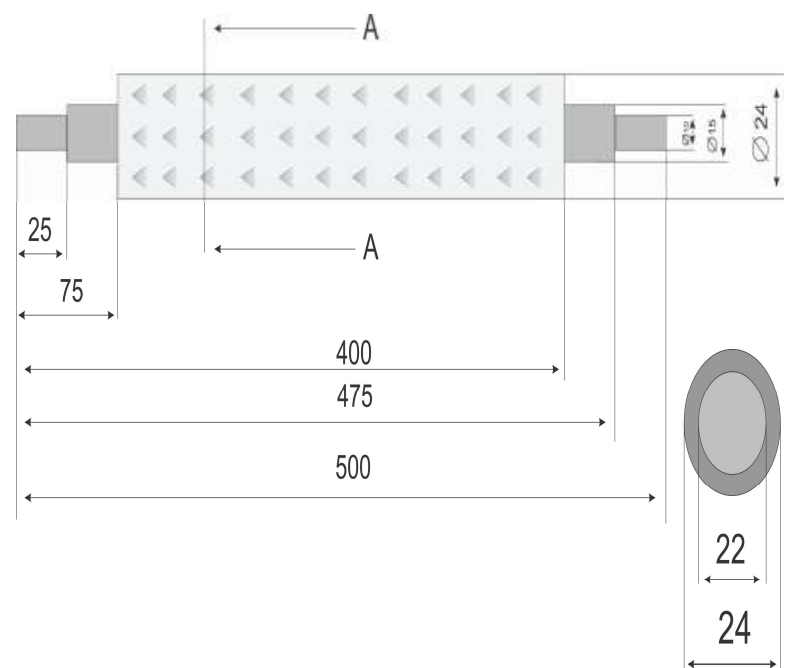

Gambar 3. Desain Detail Pemarut. 


\subsubsection{Perancangan Mesin Pemarut}

Mesin pemarut berfungsi untuk memarut dan melembutkan singkong. Seperti ditunjukkan pada gambar 2, mesin pemarut terdiri dari hoper, pemarut yang terbuat dari bahan pipa dan plat stainless, motor listrik, mounting dan gear motor.

Perancangan dan proses pembuatan bagian pemarut dari mesin pemarut ini dilakukan dengan memperhatikan sifat dan kekerasan umbi singkong $\left(3,48 \mathrm{~kg} / \mathrm{mm}^{2}\right)$. Detail desain bagian pemarut dapat ditunjukkan pada gambar 3. Bahan pembuat pemarut adalah besi stainless steel SS 316, sedangkan bahan untuk bagian shaff adalah $184 \mathrm{PH}$. Sisi samping kiri dan kanan dengan ball bearing karena hanya untuk menahan gaya radial. Rangka housing grinder dengan bahan plat stainless steel SS205. Outlet dari mesin pemarut hasilnya akan masuk ke mesin extruder.

\subsubsection{Perancangan Mesin Ekstruder}

Desain mesin extruder pemeras santan umbi singkong dan pemeras fin masing masing dapat ditunjukkan pada gambar 4 dan gambar 5. Bagian extruder fin terdiri atas bagian shaff, extruder fin dan bearing shaff. Bahan pembuat extruder fin adalah besi stainless steel SS 316, sedangkan bahan untuk bagian shaff adalah $184 \mathrm{PH}$.

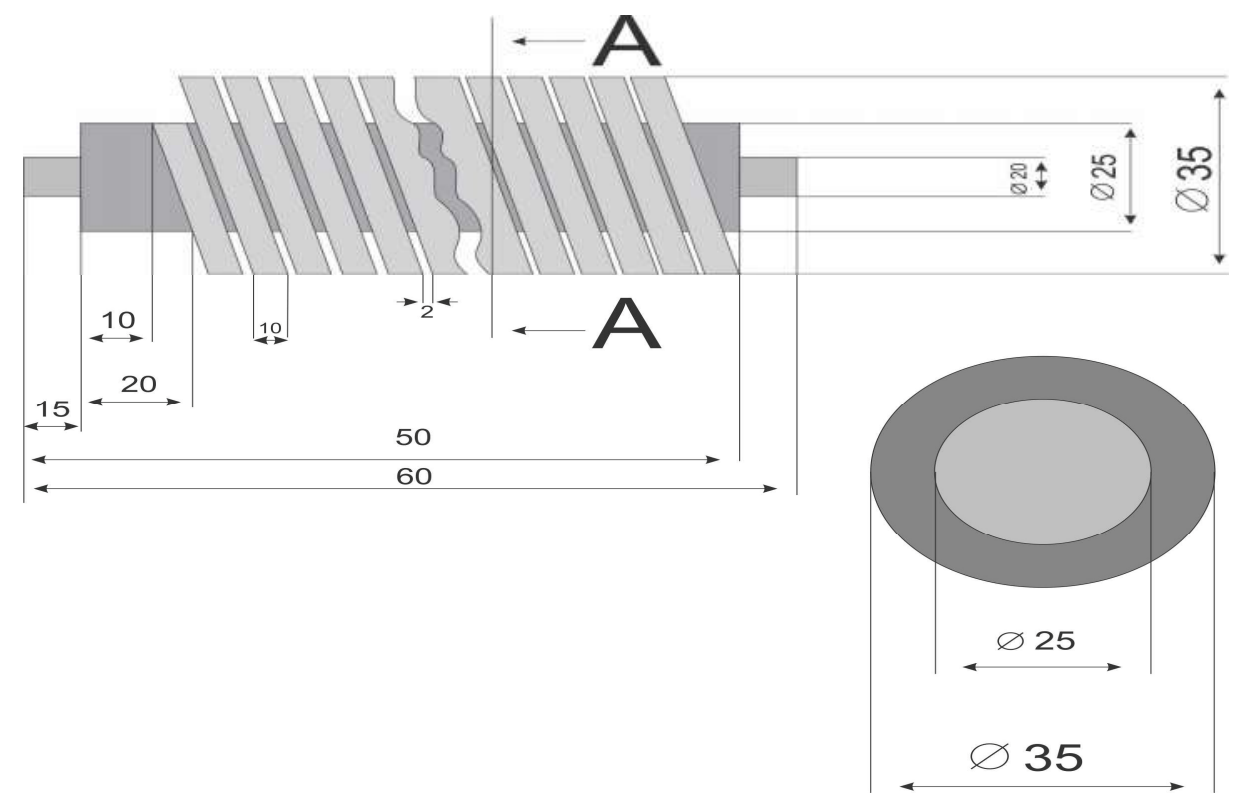

Gambar 4. Desain Detail Pemeras.

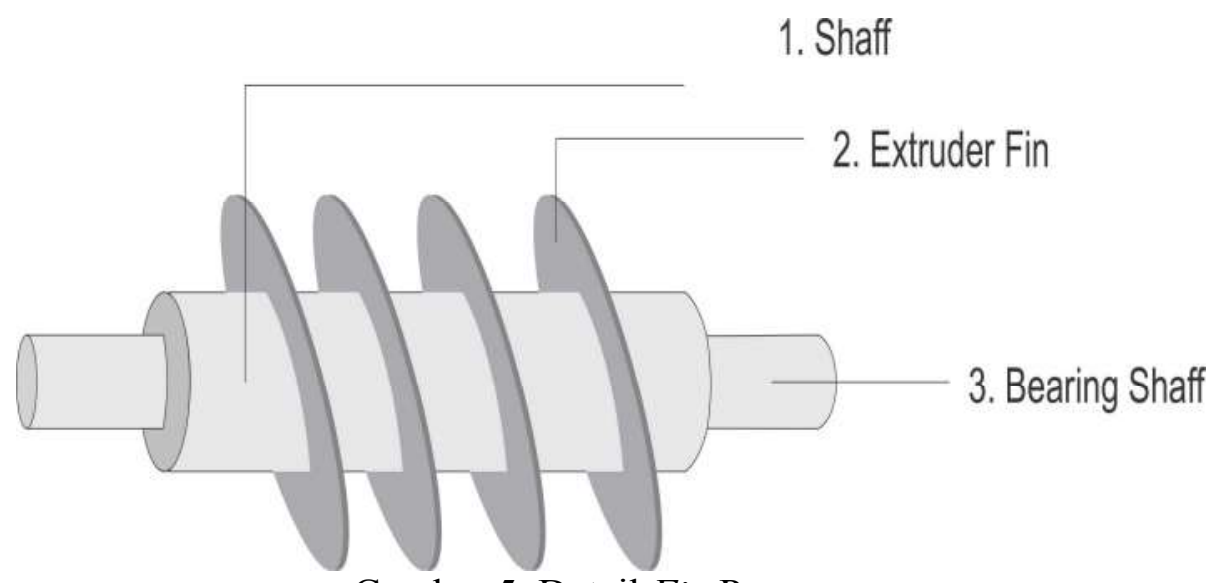

Gambar 5. Detail Fin Pemeras. 
Tabel 1. Spesifikasi Mesin

\begin{tabular}{ccc}
\hline No & Bagian Mesin & Spesifikasi \\
\hline 1 & Motor & $1 \mathrm{HP}, 1400 \mathrm{rpm}$ \\
2 & Sabuk V & Type A42 \\
3 & Pully pemarut & $50 \mathrm{~mm}$ \\
4 & Pully pemeras & $100 \mathrm{~mm}$ \\
5 & Pully motor & $30 \mathrm{~mm}$ \\
6 & Pully gearbox & $50 \mathrm{~mm}$ \\
7 & Diameter pemarut & $24 \mathrm{~mm}$ \\
8 & Diameter pemeras & $35 \mathrm{~mm}$ \\
9 & Dimensi Mesin & $110 \times 55 \times 140 \mathrm{~cm}$ \\
\hline
\end{tabular}

Tabel 2. Hasil Pengujian

\begin{tabular}{cccc}
\hline Replikasi & $\begin{array}{c}\text { Berat } \\
\text { Singkong }(\mathbf{k g})\end{array}$ & $\begin{array}{c}\text { Waktu Proses } \\
\text { (menit) }\end{array}$ & $\begin{array}{c}\text { Hasil Sari Tapioka } \\
(\mathbf{m l})\end{array}$ \\
\hline 1 & 7 & 5,5 & 2300 \\
2 & 7 & 6 & 2250 \\
3 & 7 & 6,5 & 2350 \\
4 & 7 & 7 & 2400 \\
\hline & 7 & 6 & 2200 \\
\hline & Rerata & 6,2 & $\mathbf{2 3 0 0}$ \\
\hline
\end{tabular}


3. HASIL DAN PEMBAHASAN

\subsection{Hasil Perancangan Dan Cara Kerja Mesin}

Spesifikasi perancangan mesin pembuat tapioka dapat dilihat pada tabel 1. Sedangkan bentuk mesin dapat dilihat pada gambar 6 . Mesin yang dibuat terdiri dari dua bagian yaitu unit pemarut dan unit pemeras. Untuk menjalankan mesin ini, digunakan motor (4) yang dapat menggerakkan pemarut dan pemeras secara bersamaan. Singkong yang telah di kupas dan dicuci dimasukkan melalui inlet (1), kemudian diparut di unit pemarut (2). Unit pemarut menggunakan mekanisme pemarut berputar. Hasil parutan kemudian masuk ke dalam unit pemeras. Mekanisme pemeras menggunakan screw. Unit pemeras akan memisahkan sari tapioka dan ampas singkong. Sari tapioka akan keluar melalui outlet sari tapioka (5) dan ampas singkong akan keluar melalui outlet ampas singkong.

\subsection{Uji Coba Mesin}

Uji coba dilakukan untuk mengetahui kemampuan mesin dalam menghasilan sari tapioka. Dalam uji coba ini, data yang diambil adalah waktu proses dan hasil sari tapioka.
Langkah dalam melakukan uji coba adalah sebagai berikut :

1. Mempersiapkan alat yang diperlukan yaitu timbangan, pencatat waktu, penampung sari pati, penampung ampas singkong dan gelas ukur (beaker).

2. Menyiapkan singkong dengan dikupas, dicuci dan dipotong.

3. Menjalankan mesin dan melakukan proses pembuatan sari tapioka dan menghitung waktu proses.

4. Mengukur volume sari tapioka yang dihasilkan.

Hasil uji coba dapat dilihat pada tabel 2 . Dari hasil uji coba mesin didapatkan bahwa rerata waktu proses adalah 6,2 menit per 7 kg singkong dan menghasilkan sari tapioka rerata sebesar $2300 \mathrm{ml}$ per $7 \mathrm{~kg}$ singkong. Hal ini berarti bahwa kapasitas mesin sebesar $67,7 \mathrm{~kg} / \mathrm{jam}$ dan menghasilkan sekitar $328 \mathrm{ml}$ per $\mathrm{kg}$ singkong. Selama pengujian, mesin berjalan dengan baik sesuai dengan yang diinginkan. Proses pemarutan dan pemerasan berjalan dengan lancar. Sari tapioka dan ampas keluar dengan lancar dan tidak tercampur. 


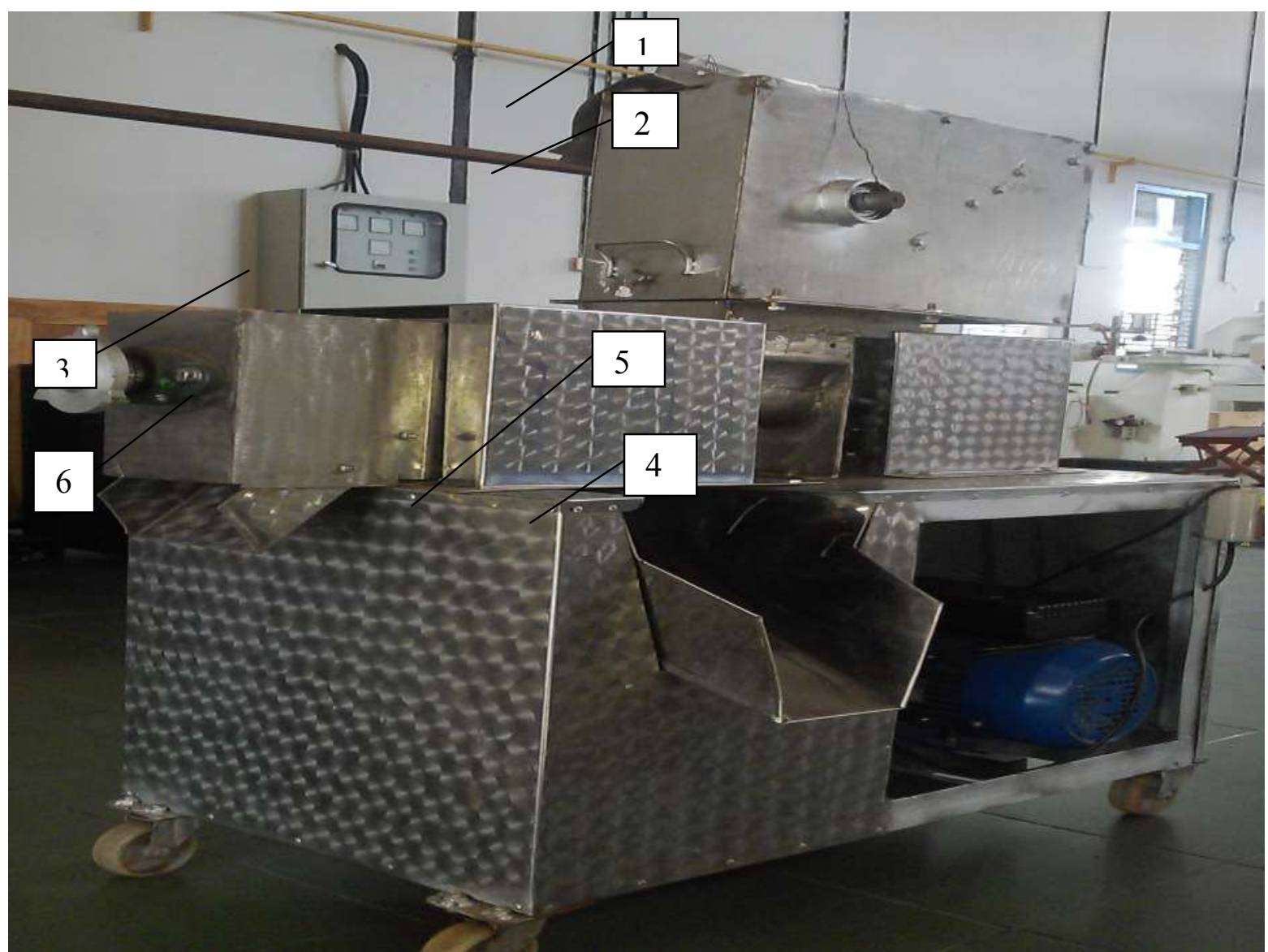

$\underline{\text { Keterangan : }}$

Gambar 6. Hasil Rancangan Mesin Tapioka.

1. Inlet Singkong.

2. Unit Pemarut.

3. Unit Pemeras.

4. Motor Penggerak Pemarut dan Pemeras.

5. Outlet Sari Tapioka.

6. Outlet Ampas Singkong.

\section{KESIMPULAN}

Dari hasil uji coba yang dilakukan, mesin dapat bekerja dengan baik. Mesin mampu memproses singkong dengan kecepatan sekitar $67 \quad \mathrm{~kg} / \mathrm{jam}$ dan menghasilkan sari tapioka dengan kapasitas sekitar $328 \mathrm{ml}$ per satu kilogram singkong. Hasil perancangan mesin melebihi dengan kapasitas yang direncanakan.

\section{Ucapan Terima Kasih}

Penulis menyampaikan ucapan terima kasih kepada Dirjen Dikti atas biaya penelitian dengan DIPA Kopertis Wilayah VII Surabaya Nomor: SP / DIPA. 023.04.1.673.453 / 2016 Revisi 01 Tanggal 03 Maret 2016. 


\section{DAFTAR PUSTAKA}

2006. Gula Singkong dapat Diproduksi di Pedesaan, Warta Penelitian dan Pengembangan Pertanian, Jakarta.

2009. Roadmap Industri Gula, Direktorat Jenderal Industri Agro Dan Kimia Departemen Perindustrian Jakarta.

Soegihardjo, O, Aninditya,. 2005. Perancangan Mesin Pembuat Tepung Tapioka, Jurnal Teknik Mesin Vol. 7, No. 1, April 2005: $22-27$.

Suripto, dkk.,. 2013. Pengembangan Gula Cair Berbahan Baku Ubi Kayu Sebagai Alternatif Gula Kristal Dengan Pendekatan Sistem Inovasi, Jurnal Teknik Industri, Volume 3 No 2, Juli 2013.

Tjokroadikoesoemo, S., 1986. HFS dan Industri Ubi Kayu Lainnya, Penerbit PT. Gramedia Jakarta. 